\title{
Impacto das Mídias Sociais no Futuro da Educação Superior no Brasil: um Estudo Prospectivo
}

\author{
Patrícia Cristina Moser, Joelson Isidro da Silva Araújo, Erika Carlos \\ Medeiros \\ Centro de Informática (CIn) - Universidade Federal de Pernambuco (UFPE) - \\ Pós-graduação em Ciência da Computação \\ 50740-560 - Cidade Universitária, Recife - PE- Brasil \\ $\{p c m 3, j$ isa, ecm 4$\}$ ecin. ufpe.br
}

\begin{abstract}
The objective of this work is to propose a prospective study about the impact that social media will have on the future of higher education in Brazil. This study used the Delphi method, where a consensus was sought in the opinions regarding the use of social media in education. Although there was a consensus among respondents about the social media trends presented, it is still noticeable that a few panelists remain neutral to their views on the use of social media and technologies applied to education by the year 2040.
\end{abstract}

Resumo. Como objetivo deste trabalho propõe-se um estudo prospectivo sobre o impacto que as midias sociais terão no futuro da educação superior no Brasil. Este estudo utilizou o método Delphi, onde buscou-se um consenso nas opiniões em relação ao uso das mídias sociais na educação. Apesar de ter havido um consenso entre os respondentes em relação às tendências de mídias sociais apresentadas, ainda percebe-se que alguns poucos painelistas se mantêm neutros às suas opiniões em relação ao uso de mídias sociais e tecnologias aplicadas à educação até o ano de 2040.

\section{Introdução}

A adoção de novas tecnologias e desenvolvimentos na mídia estão transformando o cenário da sociedade conectada, impactando na forma como indivíduos, grupos e sociedades se comunicam, trabalham, governam e, até mesmo, aprendem. Neste contexto, os alunos devem tanto saber utilizar os recursos tecnológicos quanto ter o conhecimento sobre as normas e práticas para o uso de forma apropriada no ambiente educacional. Este avanço e a diversidade do mundo globalizado impõem habilidades aos alunos para interagir com o mundo conectado, a partir do uso de ferramentas tecnológicas, questões cognitivas, uso criativo e reutilização de mídias digitais, entre outros tópicos (Meyers, 2013).

Como mídia digital, entende-se que é toda a comunicação feita através da Internet utilizando os mais diversos dispositivos, entre eles outdoors digitais, smartphones, tablets, TV digital, totens externos (Dotta, 2011). Em relação às mídias sociais, Andreas Kaplan e Michael Haenlein as definem como um grupo de aplicações para Internet construídas com base nos fundamentos ideológicos e tecnológicos da Web 2.0, e que permitem a criação e troca de conteúdo gerado. Ou seja, mídia social pode ser definida como o 
ambiente online onde as diversas informações possam ser compartilhadas, utilizando mídias digitais diversas. Dessa forma, para este estudo, estamos usando o termo "midias sociais" como algo mais amplo, de acordo com a definição de Dotta (2011).

O uso de tecnologias é amplamente considerado como um atributo essencial para o sucesso acadêmico e profisssional. Em um ambiente de educação superior cada vez mais regulado e baseado em padrões, no entanto, há uma falta de orientação clara sobre o que constitui a natureza do nível apropriado de alfabetização digital que os graduados precisam demonstrar. Apesar dessa afirmação, a capacidade dos alunos de usar a tecnologia de maneira apropriada é parte integrante da expectativa do contexto de uso de artefatos tecnológicos, incluindo competências para o consumo crítico de informações e a atenção da mídia gerenciada (McMahon, 2014).

Além disso, deve-se considerar que o aluno mudou. E em parte, em função da rápida difusão da tecnologia digital nas últimas décadas do século XX. Em um estudo realizado em 2001, Prensky afirmou que os estudantes daquela época representavam as primeiras gerações que cresceram com esta nova tecnologia. Tais estudantes passaram a vida inteira cercados e usando computadores, vídeo games, software de música digitais, câmeras de vídeo, telefones celulares, e todos os outros brinquedos e ferramentas da era digital. Este estudo indicou que, em média, um aluno graduado passou menos de 5.000 horas de sua vida lendo, mas acima de 10.000 horas jogando vídeo games (sem contar as 20.000 horas assistindo à televisão). Os jogos de computadores, e-mail, a Internet, os telefones celulares e as mensagens instantâneas são partes integrais de suas vidas. Como resultado deste ambiente onipresente e o grande volume de interação com a tecnologia, os alunos de hoje pensam e processam as informações bem diferentes das gerações anteriores.

Dado todo este contexto, torna-se relevante investigar o impacto das mídias sociais no futuro da educação superior no Brasil. A janela temporal para este trabalho foi definida com base em um dos estudos que sustentam essa pesquisa, o qual será abordado na seção 2 .

Este artigo está estruturado da seguinte forma: além desta introdução, a seção 2 aborda o referencial teórico para sustentar o presente estudo; a seção 3 apresenta o método de pesquisa utilizado; os resultados obtidos estão descritos na seção 4; as considerações finais na seção 5 e as referências estão presentes na seção 6 .

\section{Referencial Teórico}

$\mathrm{O}$ atual contexto social e cultural em que a sociedade está inserida desde as últimas décadas do século XX, caracterizado pela reorganização da produção em diferentes territórios e em forma de redes, tendo as novas tecnologias da comunicação e da informação como centro organizativo, coloca a globalização, a sociedade da informação e as tecnologias como elementos centrais no contexto social e cultural da atualidade. Tais elementos são percebidos e sentidos pela sociedade através de diferentes canais, e estão na base das alterações da educação (Meyers, 2013).

Esta seção aborda tal contexto, apresentando um breve discurso sobre a educação e tecnologia e em seguida faz uma síntese das tecnologias emergentes capazes de impactar o ensino. 


\subsection{Educação e tecnologia}

Estudos indicam que a tecnologia informática pode ajudar a apoiar o aprendizado e que é especialmente útil no desenvolvimento de habilidades de alto nível de pensamento crítico, análise e pesquisa científica. Porém, não é apenas o uso de computadores em salas de aula que permitirá esse suporte no aprendizado. Para isso é necessário que múltiplas perspectivas e ideologias sejam levadas em consideração (Roschelle, 2000).

O suporte ao aprendizado engloba um conjunto de habilidades, que incorpora o esquema cognitivo e social, fornecendo a base estrutural para a organização de conhecimento e habilidades digitais, as quais vão determinar a eficácia do método (McMahon, 2014). Para Yirula (2011), não há dúvidas quanto ao envolvimento dos alunos com todas as ferramentas tecnológicas disponíveis, mas existem pontos positivos e negativos a serem analisados. Como negativos, a autora destaca: a) a gama de informação é muito grande fazendo com que os alunos consumam apenas tópicos e não se aprofundem em determinados temas; b) há uma tendência de não checar a veracidade da informação, fazendo com que o aluno consuma determinado tópico e possa assumir a afirmativa como verdade absoluta; c) como há a tendência de o aluno assumir determinadas afirmações como verdades, isto pode comprometer seu senso crítico.

Além destes pontos negativos, há alguns desafios a serem vencidos pelo professor que quiser fazer uso das mídias sociais no seu processo de ensino: a) vencer a dispersão que algumas mídias sociais (como as redes sociais) podem provocar no aluno; b) fazer com que o uso de algumas mídias sociais (como as redes sociais) não torne o aluno um ser isolado, fazendo-o discutir menos com meio que o cerca; c) fazer com que a linguagem própria criada em algumas mídias sociais (como as redes sociais) não prejudique a qualidade da escrita e vocabulário dos alunos (Yirula, 2011).

Alguns pontos abordados pela autora tendem a ser relevantes dentro do cenário do uso de mídias sociais associada a métodos de ensino. É desejável que o aluno tenha pensamentos rápidos, o que os faria profissionais com a capacidade de resolver problemas do dia a dia de forma mais instantânea. A dinâmica (quase instantânea das mídias sociais) criou no aluno o hábito de reações rápidas favorecendo a velocidade de pensamento, qualidade apreciada no mundo profissional.

Dessa forma, é necessário entender os processos de ensino e aprendizagem e as tecnologias atuais e futuras, de forma a compreender como as tecnologias são capazes de impactar o ensino. Isto será abordado na próxima seção.

\subsection{Tecnologias emergentes capazes de impactar o ensino}

Nesta seção são apresentadas e analisadas algumas tecnologias capazes de impactar o ensino no futuro, mencionadas em três estudos: a) o infográfico de Zappa (2012) sobre o futuro da tecnologia educacional até o ano de 2040; b) as tecnologias apresentadas na edição K-12 da NMC Horizon Report (2014); e c) o trabalho realizado por Peter Stone (2016) em conjunto com um grupo de pensadores acadêmicos da Universidade de Stanford.

Conforme Zappa (2012), apesar do desenvolvimento tecnológico provocar mudanças na educação, na prática da sala de aula, as mudanças não ocorrem na velocidade que se espera. Em uma das suas produções mais populares, ele produziu um infográfico sobre o futuro da educação que foi considerado um dos mais importantes de 2012 e tendências indicadas neste artefato já podem ser observadas. Tal infográfico pode 
ser visualizado em https://bit.ly/2U1JOCw. Nele, foi traçada uma linha de tempo que vai até 2040 e contendo seis temas centrais: 1) tecnologia é fixa no laboratório ou sala de aula; 2) utilização universal e móvel da tecnologia; 3) alunos livres para colaborar com pares de todo o mundo; 4) salas de aula físicas tendem a ser substituídas por oficinas ou ambientes virtuais; 5) avaliação tradicional é substituída por análise de desempenho em projetos e em portfólios e 6) educação como esforço contínuo interligado, que permite lidar com o mundo em perpétua mudança. Tais temas se subdividem, se entrelaçam e se apresentam em três espaços distintos: 1) as salas de aula, 2) as oficinas e 3) os ambientes virtuais.

Com a previsão de Zappa para 2040, ensinar e aprender, bem como o ambiente de sala de aula, será bastante diferente da forma como é hoje. Haverá uma adoção em massa de várias formas de tecnologia para alavancar recursos especializados e conectividade. Um número significativo de atividades de aprendizado está se movendo para aprendizagens individualizadas, just-in-time e abordagens colaborativas. Haverá uma transição da sala de aula centrada no professor para aprendizado híbrido ou combinado, que mistura componentes de e-learning com reuniões de classe face a face menos frequentes. A avaliação da aprendizagem levará em conta resultados e capacidades de aprendizagem mais orientados individualmente e que sejam relevantes para o domínio do sujeito e a competência global. Os professores terão um papel importante como designer de aprendizado - incorporando os recursos disponíveis em ambientes virtuais de aprendizagem.

O segundo estudo vem da série "Horizon Reports", do New Media Consortium (NMC), um empreendimento de pesquisa abrangente, estabelecido em 2002. O estudo identifica e descreve tecnologias emergentes suscetíveis de ter um grande impacto no ensino, aprendizagem e investigação criativa dentro do ambiente de ensino nos próximos anos.

O trabalho, desenvolvido por Johnson, Becker, Estrada, and Freeman (2014), afirma que o desenvolvimento da tecnologia na educação para os próximos anos permeará sobre Bring Your Own Devices (BYOD), Cloud Computing, Games e Gamification, Learning Analytics, The Internet of Things e Wearable Technology. Porém, a partir dos tantos desenvolvimentos previstos pelo NMC no ensino e na aprendizagem, apenas alguns estão sendo utilizados, implementados ou integrados no processo de ensino, os demais citados são tendências para os próximos anos.

O terceiro estudo é coordenado por um painel de pensadores acadêmicos e industriais, que olhou para 2030 para prever como os avanços na inteligência artificial (IA) podem afetar áreas diversas, entre elas, a educação. Intitulado Artificial Intelligence and Life in 2030, esta investigação é o primeiro produto do One Hundred Year Study on Artificial Intelligence (AI100). O estudo fornece uma base realista para discutir como as tecnologias de IA podem afetar a sociedade (Stone at al, 2016).

As escolas e as universidades estão lentas em adotar as tecnologias da IA, mesmo que isso possa impulsionar a aprendizagem online, fazendo com que os professores multipliquem as salas de aula, e se tornem capazes de trabalhar com as necessidades e estilos de aprendizagem de forma individual. Isso se deve à falta de fundos e à falta de evidências sólidas desse suporte no aprendizado dos alunos. A expectativa é que o uso de tutores inteligentes e outras tecnologias de IA se expandam significativamente, bem como a aprendizagem baseada em apps de realidade virtual. 
As tecnologias citadas nesta seção e apresentadas por Zappa (2012), NMC Horizon Report (2014) e Stone (2016), embasam este estudo prospectivo. A metodologia para este trabalho está detalhada na próxima seção.

\section{Método}

Para condução deste estudo, foi empregado um método prospectivo, denominado Delphi. Conforme Oliveira, Costa e Wille (2008), este método é empregado para conhecer a probabilidade de eventos futuros e é usado em um número significativo de pesquisas em diversas áreas. Este método faz o uso de painéis que são construídos para buscar uma estruturação de conceitos e para projetar futuros (Sáfadi, 2001).

Durante o seu processo busca-se um consenso para representar a consolidação do julgamento intuitivo de um grupo de peritos sobre tendências e eventos futuros. Para isso, o método se baseia no uso estruturado do conhecimento, da experiência e da criatividade de um painel de especialistas, pressupondo-se que o julgamento coletivo, quando organizado adequadamente, é melhor que a opinião de um só indivíduo (Wright e Giovinazzo, 2000). As características essenciais deste método são a troca de informações e opiniões entre os respondentes, o anonimato das respostas e a possibilidade de revisão de visões individuais sobre o futuro, diante das previsões e argumentos dos demais respondentes (Wright e Giovinazzo, 2000).

Conforme mencionado anteriormente, este estudo prospectivo se baseou em três trabalhos que analisaram tecnologias capazes de impactar o ensino no futuro: a) o infográfico de Zappa (2012); b) as tecnologias apresentadas pela Horizon Report (2014); e c) o trabalho realizado por Peter Stone (2016). Dessa forma, a janela temporal definida neste estudo foi limitada pelo trabalho apresentado por Zappa (2012), que apresenta uma visão para até 2040 .

A seguir, serão apresentadas mais detalhes sobre cada uma das fases adotadas neste estudo.

\subsection{A escolha dos especialistas e elaboração do questionário}

De acordo com o contexto explorado neste estudo, o grupo de painelistas selecionados foi formado por professores universitários de uma IES em Pernambuco, especialistas em mídias sociais e que fazem o uso da tecnologia em sala de aula.

Ao todo, 16 potenciais respondentes foram convidados e informados sobre o objetivo e importância do estudo. Destes, 9 aceitaram o convite para participar da pesquisa. Em seguida, os questionários foram enviados por email individualmente, preservando o anonimato dos demais participantes. Dentre os 9 participantes, obtivemos a resposta de 7 . De posse das respostas, passamos à tabulação e análise, procurando associar os principais argumentos às diferentes tendências das respostas. Após esta análise, surgiu a necessidade de realizar uma $2^{\mathrm{a}}$ rodada. Os 7 especialistas receberam um novo questionário e destes, 6 profissionais responderam. A tabulação e resultado das respostas será apresentada na seção 4.

Embora não haja regras rígidas quanto ao formato das questões de um questionário Delphi, algumas recomendações podem ser seguidas para se evitar erros na sua elaboração (Martino, 1993). Estes erros podem fazer com que os painelistas percam muito tempo para transmitir as informações ou deixem de responder a alguma questão por falta de entendimento. 
Seguindo as recomendações propostas por Martino (1993), o questionário elaborado para esta pesquisa foi baseado nos estudos de Zappa (2012), NMC Horizon Report (2014) e Stone (2016) sobre tecnologias para a educação até o ano de 2040. Para cada questão, foi apresentada uma síntese das principais informações conhecidas sobre o assunto e, eventualmente, extrapolações para o futuro, de forma a homogeneizar linguagens e facilitar o raciocínio orientado para o futuro.

Para a $1^{\mathrm{a}}$ rodada, foram apresentadas 08 questões, onde seis delas eram abertas, exigindo justificativa e sem delimitação de espaço para a argumentação. $\mathrm{Na} 2^{\mathrm{a}}$ rodada, foram apresentadas 18 questões, todas elas fechadas.

\subsection{A aplicação e tabulação do questionário}

Na primeira rodada, um questionário A foi elaborado de modo a obter informações sobre sobre o uso das mídias sociais na educação. Após a análise das respostas, surgiu a necessidade de realizar uma $2^{\mathrm{a}}$ rodada (sendo aplicado um questionário $\mathrm{B}$ ), a fim de se chegar a um consenso entre os especialistas. Ressalta-se, neste momento, que podem ser rodados tantos questionários quanto necessários, até que se consiga uma convergência de opiniões sobre o assunto pesquisado (Oliveira, Costa e Wille, 2008).

A segunda rodada do questionário apresentou, obrigatoriamente, os resultados do primeiro questionário, possibilitando que cada respondente pudesse rever sua posição face à previsão e argumentação do grupo, em cada pergunta. O questionário $\mathrm{B}$ foi gerado a partir das respostas obtidas no primeiro, devidamente analisadas e agrupadas pela similaridade de conteúdo, com base em palavras chaves; as mesmas questões foram utilizadas, desta vez já trazendo alternativas que representavam o consenso da maioria dos pesquisadores. Por incluir os resultados da rodada anterior e, ocasionalmente, as novas questões que foram levantadas, o questionário $\mathrm{B}$ foi mais extenso que o primeiro.

A tabulação mereceu cuidado especial, principalmente na primeira etapa (questionário $\mathrm{A}$ ), que exigiu uma interpretação das respostas às questões abertas. No questionário $\mathrm{B}$, usou-se, para as respostas, a escala de likert. As respostas obtidas na segunda etapa evidenciaram grande convergência de opiniões e, tendo atingido um consenso, não houve a necessidade de uma terceira rodada.

\section{Análise dos Resultados}

Os resultados aqui descritos estão de acordo com os dados obtidos através do questionário $\mathrm{B}$, da $2^{\mathrm{a}}$ rodada. Os questionários utilizados podem ser consultados em https:// https://bit.ly/2OVg8Wq (questionário A) e https:// https://bit.ly/31CIHsY (questionário B). Como um dos estudos base desta pesquisa traça uma linha de tempo que vai até 2040 (Zappa, 2012), as questões do questionário levam em consideração décadas distintas (2020, 2030 e 2040). Para facilitar o entendimento, serão apresentados os contextos das perguntas aplicadas e, em seguida, uma análise dos dados. Por questões de limitação de espaço, não apresentamos todos os gráficos produzidos com os resultados do questionário.

A questão 1 do questionário refere-se às habilidades do professor, onde foi solicitado que o respondente marcasse, dentre as alternativas, qual o grau de concordância em relação às habilidades que poderão ser necessárias ao professor. A distribuição dos resultados obtidos estão descritos na Figura 1. 


\begin{tabular}{|l|l|l|l|l|l|}
\hline & Discordo Totalme & Discordo & Neutro & Concordo & Concordo Totalmente \\
\hline Habilidades com tecnologia & $0 \%$ & $0 \%$ & $17 \%$ & $0 \%$ & $83 \%$ \\
\hline Habilidade de escrita de copyright & $0 \%$ & $33 \%$ & $33 \%$ & $17 \%$ & $17 \%$ \\
\hline $\begin{array}{l}\text { Percepção da linguagem apropriada para cada midia } \\
\text { digital utilizada }\end{array}$ & $0 \%$ & $0 \%$ & $33 \%$ & $33 \%$ & $33 \%$ \\
\hline $\begin{array}{l}\text { Disposiçăo a entrar em modelos disruptivos de } \\
\text { educaçắo }\end{array}$ & $0 \%$ & $17 \%$ & $0 \%$ & $17 \%$ & $67 \%$ \\
\hline
\end{tabular}

Figura 1: Habilidades necessárias ao professor. Fonte: Autores

A maioria dos respondentes concordam com a necessidade de o professor possuir habilidades com tecnologia. Nenhum respondente discorda totalmente sobre a necessidade dos professores adquirirem as quatro habilidades. Nota-se que a convergências nas respostas é forte em relação a necessidade de o professor possuir habilidades com tecnologia em um futuro próximo, a fim de que a educação possa sair do tradicionalismo.

A questão 2 refere-se ao uso de plataformas móveis para as próximas duas décadas, a fim de tornar a comunicação constante no processo de ensino-aprendizagem. Houve confirmação, por parte dos respondentes, em acreditar que todos os aparatos tecnológicos citados no estudo serão necessários para tornar a uso da tecnologia universal e móvel. Os resultados estão descritos na Figura 2.

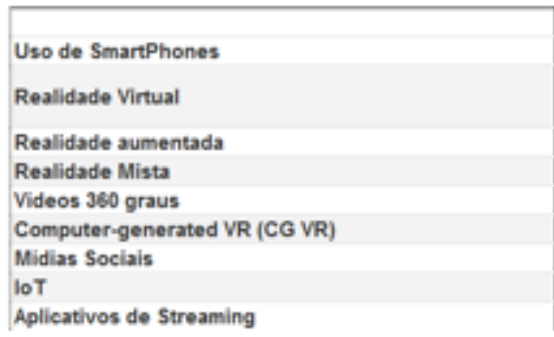

Figura 2: Tecnologias associadas à educação. Fonte: Autores

As questões 3 e 4 foram direcionadas à colaboração. Houve um consenso de que os alunos serão livres para colaborar com pares de todo o mundo até 2020 , e que a colaboração é um processo inerente à educação. Nenhum respondente discorda desta tendência.

As questões 6 e 7 referem-se a ambientes virtuais de aprendizagem e à evolução constante da conectividade e o uso crescente da internet, trazendo opções que justifiquem a tendência de que as salas de aula físicas sejam substituídas por oficinas ou ambientes virtuais de aprendizagem até 2030. Verificou-se que há um consenso entre os painelistas sobre esta tendência, ou que estes recursos estejam cada vez mais presentes no dia a dia das escolas e universidades. Isso se justifica pela evolução constante da conectividade anywhere, além do uso crescente da Internet, de dispositivos móveis, bem como de aplicativos para colaboração. Nenhum respondente discorda da tendência.

As questões 9 e 10 abordam formas de avaliação. Uma das questões que mais se percebe como desfavorável à medição da evolução e aprendizagem do aluno é a forma de avaliação tradicional. Há uma tendência até 2030 que o uso das mídias digitais na educação sugere a substituição das avaliações tradicionais pela avaliação em projetos ou portfólios. Pelas respostas, $83 \%$ dos painelistas acreditam nesta tendência. A avaliação por projetos pode retratar a vida profissional no mundo acadêmico, uma forma de trazer 
a prática para a academia e haver uma evolução no modelo de avaliação. Importante ressaltar que nenhum respondente discordou desta tendência.

A questão 12 refere-se à educação como esforço constante. Há uma tendência de que até 2040 a educação poderá ser vista como esforço contínuo, interligado, que permite lidar com o mundo em perpétua mudança. $67 \%$ dos respondentes acreditam nesta tendência. Apesar de 33\% dos painelistas se manterem neutros, não houve discorância quanto a esta tendência.

A questão 13 diz respeito ao fato de que o acesso à informação está facilitado, podendo tornar o processo de aprendizado contínuo e atemporal, levando a aprendizagem a ser um processo distribuído ao longo do dia. 100\% dos respondentes concordam totalmente com esta tendência.

As questões 15 e 16 referem-se ao uso da inteligência artificial e neurociência como forma de gerar indicadores para direcionar o aprendizado, podendo entender o comportamento de cada aluno em sala de aula até 2040, possibilitando que os conteúdos sejam entregues de acordo com a personalidade do estudante, potencializado a aprendizagem. Tais tecnologias poderiam possibilitar uma melhor estratificação dos dados, favorecendo o processo de educação como um todo. Os painelistas acreditam que tanto a inteligência artificial quando a neurociência serão tecnologias facilitadoras na estratificação de dados, permitindo a personalização do ensino.

A questão 18 se refere à tecnologias que podem impactar na educação até 2030 . Uma pequena parte dos respondentes discordam que em relação à BYOD, IoT e Weareble Technology, mas a maioria concorda que todas as tecnologias listadas permearão a educação até 2030, sendo destaques Cloud Computing e Games e Gamification. Isto pode ser observado na Figura 3.

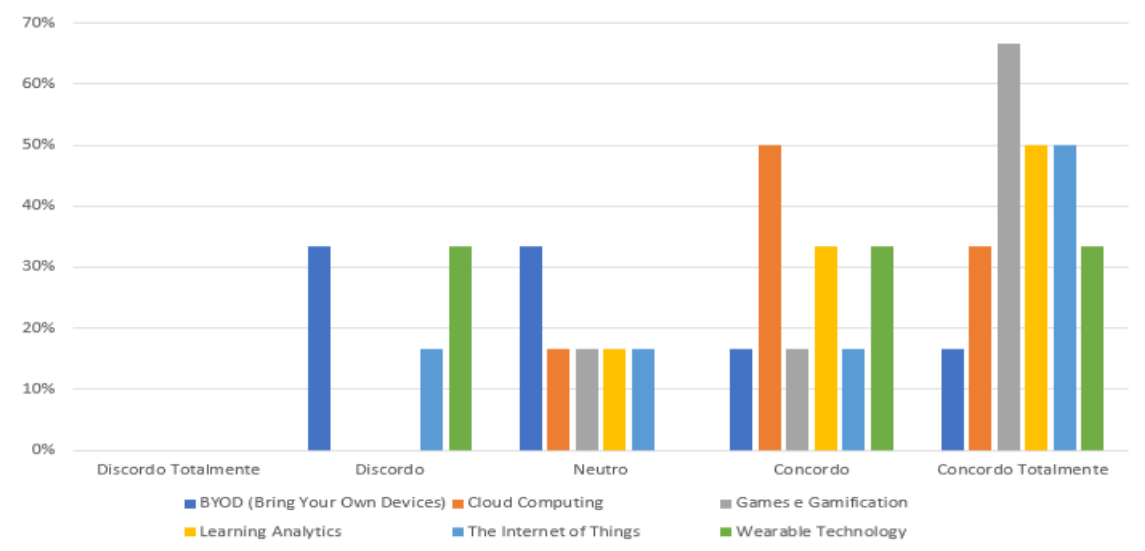

Figura 3: Tecnologias que podem impactar na educação até 2030. Fonte: Autores

As questões 5, 8, 11, 14 e 17 apontavam justificativas para o caso de haver discordância por parte dos especialistas em relação às tendências apresentadas. Como não foram obsevadas discordâncias, tais questões não foram analisadas.

Com base nas análises dos resultados, pode-se constatar que houve uma convergência de opiniões, na percepção dos respondentes, sobre a tendência da utilização mídias sociais, utilizando tecnologias de mídia digitais, associadas à educação no Brasil até 2040. 


\section{Conclusão}

O presente trabalho teve como objetivo a realização de um estudo prospectivo para investigar o impacto das mídias sociais no futuro da educação superior no Brasil, até o ano de 2040. Foram apresentadas as principais tendências de tecnologias de mídias sociais que podem impactar na educação. Empregamos o método Delphi como forma de obter um consenso por parte de um grupo de especialistas. Os três estudos brevemente descritos na Subseção 2.2 ofereceram suporte ao questionário aplicado.

Como resultados, há uma convergência forte das respostas em relação a necessidade de o professor possuir habilidades com tecnologia em um futuro próximo, a fim de que a educação possa sair do tradicionalismo. Bem como, sobre o uso de plataformas móveis para as próximas duas décadas, tornando a comunicação constante no processo de ensino-aprendizagem. O mesmo se observa para o uso de dispositivos para tornar a uso da tecnologia universal e móvel. Além disso, há um consenso de que os alunos serão livres para colaborar com pares de todo o mundo até 2020, e que a colaboração é um processo inerente à educação.

A evolução constante da conectividade anywhere, além do uso crescente da Internet, de dispositivos móveis, bem como de aplicativos para colaboração, justificam a tendência de que até 2030 as salas de aula físicas sejam substituídas por oficinas ou ambientes virtuais de aprendizagem, indicando que pode haver a substituição das avaliações tradicionais pela avaliação em projetos ou portfólios, de forma trazer a prática para a academia e haver uma evolução no modelo de avaliação. Além disso, até 2040 a educação poderá ser vista como esforço contínuo, e a aprendizagem, um processo distribuído ao longo do dia, tornando o processo de aprendizado contínuo e atemporal.

$\mathrm{O}$ uso da inteligência artificial e neurociência podem gerar indicadores acerca do comportamento de cada aluno em sala, permitindo a estratificação dos dados e a personalização do ensino, potencializado a aprendizagem. Observa-se, também, que existe uma tendência de que o desenvolvimento da tecnologia na educação permeará sobre diversas tecnologias, destacando-se Cloud Computing e Games e Gamification.

Apesar de ter havido um consenso entre os painelistas, ainda percebe-se que alguns poucos especialistas se mantêm neutros às suas opiniões. Apesar de não ter havido discordância, mas dado que a metodologia empregada busca a convergência das respostas, é sugerível uma nova rodada de questionários, para que as respostas tenham uma convergência total em relação ao impacto das mídias sociais na educação até 2040.

\section{Referências}

Dotta, S. (2011). Uso de uma Mídia Social como Ambiente Virtual de Aprendizagem. Congresso Brasileiro de Informática na Educação. Disponível em: $<$ http://brie.org/pub/index.php/sbie/article/view/1623> Acesso em: 20 nov. 2017.

Johnson, L.; Adams, B.S.; Estrada, V.; Freeman, A.(2014). NMC Horizon Report: 2014 K-12 Edition. Austin, Texas: The New Media Consortium.

KAPLAN, A. M; HAENLEIN, M. (2010). Users of the world, unite! The challenges and opportunities of Social Media. Business horizons. Elsevier.

Martino, J. P. (1993). Technological forecasting for decision making. 3. ed. New York: Mc Graw-Hill Inc.

McMahon, M. (2014). Ensuring the development of Digital Literacy in higher education 
curricula. Proceedings of Annual Conference of the Australasian Society for Computers in Learning in Tertiary Education. Dunedin, New Zealand.

Meyers, E. M.; Erickson, I.; Small, R.V. (2013). Digital literacy and informal learning environments: an introduction. Learning, Media and Technology.

NMC Horizon Report. (2014). K-12 Edition. Disponível em: < https://www.nmc.org/publication/nmc-horizon-report-2014-k-12-edition>. Acesso em: 20 nov. 2017.

Oliveira, J.S.P; Costa, M.M, Wille, M.F.C. (2008). Introdução ao método Delphi. Curitiba: Mundo Material.

Prensky, M. (2001). Digital Natives, Digital Immigrants Part 1. On the Horizon, Vol. 9 Issue: 5, https:// doi.org/10.1108/10748120110424816 Acesso em: 20 nov. 2017.

Roschelle, J.M; Pea, R.D.; Hoadley, C.M.; Gordin, D.N; Means, B.M. (2000). Changing How and What Children Learn in School with Computer-Based Technologies, The Future of Children, Children and Computer Technology.

Sáfadi, C.M.Q. (2001). Delphi: um estudo sobre sua aceitação. In: V SEMEAD, 2001. São Paulo: Anais... SEMEAD FEA-USP.

Stone, P. at al. (2016). Artificial Intelligence and Life in 2030. One Hundred Year Study on Artificial Intelligence: Report of the 2015-2016 Study Panel.

Wright, J.; Giovinazzo, R. (2000). Delphi: uma ferramenta de apoio ao planejamento prospectivo. Caderno de Pesquisas em Administração.

Yirula, C.P. (2011), Os 10 Grandes impactos das mídias sociais na educação. Disponível em: $\quad<$ https://cadernodia.wordpress.com/2011/07/23/redes-sociais-e-educacao-umarelacao-de-amor-e-odio/> Acesso em: 20 nov. 2017.

Zappa, M. (2012). Inforgráfico: FutureWork - Trends and Challenges for Work in 21st Century.

Disponível

em: $<$ http://www.webaula.com.br/index.php/pt/acontece/noticias/2781-infograficoapresenta-o-futuro-das-tecnologias-na-educacao/>. Acesso em: 20 nov. 2017. 